\title{
Experimental evaluations of radio frequency heating in low-moisture agricultural products
}

\author{
Peizhen Zhang ${ }^{1}$, Hankun Zhu', Shaojin Wang ${ }^{1,2 *}$ \\ ${ }^{1}$ Northwest A\&F University, College of Mechanical and Electronic Engineering, Yangling, Shaanxi 712100, China, ${ }^{2}$ Department of Biological \\ Systems Engineering, Washington State University, 213 L.J. Smith Hall, Pullman, WA 99164-6120, USA
}

\section{A B S T R A C T}

\begin{abstract}
Radio frequency (RF) heating is considered as a potential postharvest technology for disinfesting agricultural products. Heating uniformity is one of the biggest problems in practical applications of RF technology. In this study, three different comparison experiments were conducted to evaluate the heating uniformity in a $6 \mathrm{~kW}, 27.12 \mathrm{MHz}$ parallel plate RF heating system with a free-running oscillator. The three sample conditions in RF heating experiments include four different thicknesses milled rice placed in the container, the milled rice of $9 \%$ and $11 \%$ moisture content with $4 \mathrm{~cm}$ thickness, and milled rice and soybean with $4 \mathrm{~cm}$ thickness and $9 \%$ moisture content in the half section of the container. Finally the milled rice sample with low moisture in the corner and high moisture in the center of the container was used to evaluate the heating uniformity improvement. The results showed that the milled rice temperature increased with increasing thickness. Temperatures in corners and edges were higher than those in the center both in RF treated rice and soybeans. The samples of rice or with high moisture content were heated more than those of soybean or with low moisture content. The RF heating uniformity could be improved by placing the low moisture samples in the corner and high moisture ones in the center. This study should provide useful information for designing practical RF treatment processes as physical disinfesting methods.
\end{abstract}

Keywords: Radio frequency; Thermal treatment; Heating uniformity; Low-moisture agricultural products

\section{INTRODUCTION}

Radio frequency $(\mathrm{RF})$ energy is an electromagnetic wave with a wide band of frequencies ranging from $1 \mathrm{MHz}$ to $300 \mathrm{MHz}$ and has been widely used for industrial applications, such as drying of woods, textiles, paper and cardboard, and post-backing of biscuits (Metaxas and Clee, 1993). Especially recently, RF treatments have been extensively studied for postharvest disinfestations (Hou et al., 2014; Jiao et al., 2012; Lagunas-Solar et al., 2007; Shrestha and Baik, 2013; Wang et al., 2007; Wang and Tang, 2001; Wang et al., 2002; Wang et al., 2010) and pasteurizations (Gao et al., 2012; Jeong and Kang, 2014; Kim et al., 2012) in low-moisture agricultural products due to rapid and volumetric heating. But the non-uniform heating is still a major obstacle for RF treatment technology to be applied in the agricultural product processing industry.

Non-uniform RF heating may result in insect or microbial survival in cold spots and quality degradation in hot spots.
This under or over-heating in products is mainly caused by the feeding and conductance locations on the top electrode in RF systems (Wang et al., 2015; Zhu et al., 2014), and sample locations, shape and properties (Birla et al., 2008; Huang et al., 2015a; Tiwari et al., 2011). The major overheating has been observed in spherical fresh fruit core (Birla et al., 2008; Tiwari et al., 2008; Wang et al., 2006) and edges or corners of dry products in rectangular containers (Hou et al., 2014; Huang et al., 2015b; Ling et al., 2014). After the RF unit has been installed, only the sample characteristics could be determined and adjusted to improve the RF heating uniformity.

Heating uniformity improvements have been conducted in RF systems both using experiments (Hou et al., 2014; Wang et al., 2010; Zhou et al., 2015) and computer simulations (Huang et al., 2015b; Tiwari et al., 2011; Wang et al., 2005; Jiao et al., 2014; 2015a, b). Most of these researches are focused on processing parameters, such as hot air surface heating, moving and mixing but not on the sample's properties (Pan et al., 2012;

\footnotetext{
${ }^{*}$ Corresponding author:

Shaojin Wang, Ph.D, Professor, Northwest A\&F University, College of Mechanical and Electronic Engineering, Yangling, Shaanxi 712100 , China. Tel.: +86-29 87092319, Fax: +86- 29 87091737, E-mail: shaojinwang@nwsuaf.edu.cn
} 
Wang et al., 2010; Zhou et al., 2015). Initial research results show that rectangular shape containers provide the similar heating uniformity in squared, sphere, and cylinder ones (Alfaifi et al., 2014; Birla et al., 2008) and have thus been widely used in RF heating (Hou et al., 2014; Jiao et al., 2012; Tiwari et al., 2011). The samples located in the center of the RF cavity are an acceptable choice for further heating uniformity tests due to similar heating pattern in other locations (Wang et al., 2014). Based on the dielectric properties theory and RF heating mechanisms, the different mixed products with different moisture contents may cause various heating rates, resulting in non-uniform RF heating (Huang et al., 2015a; Wang et al., 2015). Thus, it is essential for experimentally determining the influence of sample thickness, and mixed samples with different types and moisture contents on RF heating uniformity so as to provide practical RF treatment parameters and minimize adverse effects on product quality.

The objectives of the research were (1) to determine the temperature distributions of RF treated milled rice with 4 thicknesses, (2) to measure and compare the temperature distributions of RF heated milled rice with two moisture contents, (3) to compare the RF heating uniformity in milled rice and soybean with the same thickness and moisture content, and (4) to improve the RF heating uniformity when placing the low moisture milled rice in the corner and high-moisture one in the center parts of the container.

\section{MATERIALS AND METHODS}

\section{Materials}

Milled rice (Oryza sativa L.) and soybeans (Glycine max) purchased from a local grocery store in Yangling, Shannxi, China were selected for RF heating tests and stored at the constant temperature $\left(25^{\circ} \mathrm{C}\right)$ thermostatic and humidity controlled chamber before RF experiments. The average initial moisture contents of milled rice and soybean were $9.05 \pm 0.02 \%$ and $5.88 \pm 0.03 \%$ on wet basis, respectively. The target moisture contents in this study were adjusted by adding deionized water with predetermined amount using the previous method (Huang et al., 2015b). These moisture levels observed in real storage conditions were used to improve the RF heating uniformity.

\section{RF heating system}

A $6 \mathrm{~kW}, 27.12 \mathrm{MHz}$ parallel plate RF heating system with a free-running oscillator (COMBI 6-S, Strayfield International Limited, Wokingham, UK) was used to heat the milled rice and soybean in this study (Fig. 1a). The sample was heated between two parallel plate electrodes without additional hot air surface heating and conveyor movement. The gap between the electrode plates was adjusted to have a suitable RF power coupled to the sample, thus to obtain a required heating rate. In this study, the electrode gap of $120 \mathrm{~mm}$ and heating time of $5 \mathrm{~min}$ were used for all RF treatments.

\section{Heating container and temperature measurement}

A container (inner dimension $32.5 \mathrm{~L} \times 24 \mathrm{~W} \times 8.5 \mathrm{H} \mathrm{cm}^{3}$ ) made of polyethylene was used to load the sample. To prevent rice or soybean leakage from the container, the internal surface of the container was covered by a thin layer of plastic film with mesh opening of $1 \mathrm{~mm}$. The sample was placed directly on the bottom electrode in the center of the RF cavity. During RF heating, the sample temperature in the center was monitored by a fiber optical sensor system (HQ-FTS-D120, Xi'an HeQi Opo-Electronic Technology Co., LTD, Shaanxi, China) with an accuracy of $\pm 1{ }^{\circ} \mathrm{C}$. Based on the thermal death kinetics of most storage insect pests, 100\% inactivation could be reached when the final temperature might achieve $50{ }^{\circ} \mathrm{C}$ (Wang and Tang, 2001; Johnson et al., 2003). The RF system was turned off when the central temperature reached $50{ }^{\circ} \mathrm{C}$ in $4 \mathrm{~cm}$ thick samples. After RF heating, the sample was immediately moved out of the cavity. The whole samples in the container were divided into two layers (Fig. 2) and separated by a thin gauze (with mesh opening of $1 \mathrm{~mm}$ ) to sequentially map the horizontal surface temperature using an infrared camera (DM63-S, DaLi Science and Technology Co., LTD, Zhejiang, China) with an accuracy of $\pm 2{ }^{\circ} \mathrm{C}$. The image analysis system was used to collect and analyze the surface temperature data for each layer (Fig. 1b).

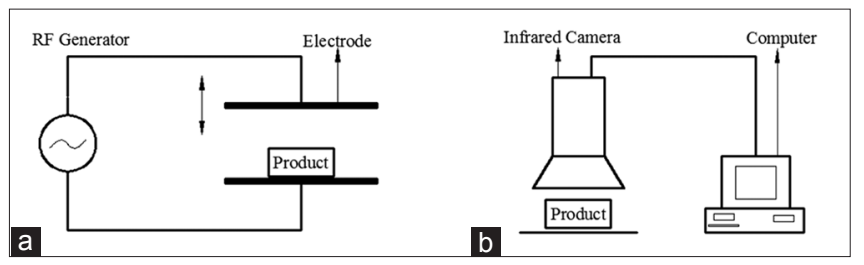

Fig 1. Schematic view of the parallel plate, $27.12 \mathrm{MHz}$ radio frequency (RF) system to treat the product (a) and the infrared imaging system to measure product surface temperature after RF treatment (b).

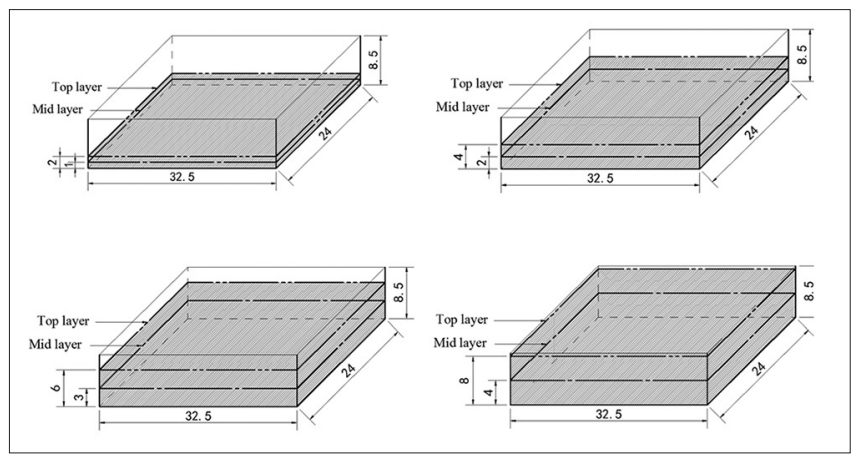

Fig 2. Rectangular plastic container separated into two layers with different thickness of milled rice for surface temperature measurements (all dimensions are in $\mathrm{cm}$ ). 


\section{Experimental procedure}

\section{RF heating in milled rice samples with 4 thicknesses}

To determine the effect of different thickness of sample in RF treatment on the heating uniformity, the milled rice with thicknesses of $2 \mathrm{~cm}(2 \mathrm{~kg}), 4 \mathrm{~cm}(3 \mathrm{~kg}), 6 \mathrm{~cm}$ $(4 \mathrm{~kg})$, and $8 \mathrm{~cm}(5 \mathrm{~kg})$ was loaded into four rectangular containers (Fig. 2). The milled rice in each container was equally divided into two layers and separated by the thin gauzes with mesh opening of $1 \mathrm{~mm}$ for temperature mapping within $20 \mathrm{~s}$ after RF heating (Fig. 1b). Prior to the $\mathrm{RF}$ treatment, the rice samples with moisture content of $9 \%$ w.b. were equilibrated at the room temperature $\left(25^{\circ} \mathrm{C}\right)$. The rice sample was placed on the center of the bottom plate. During the RF heating, the fiber optical sensor placed in the center of the sample was used to monitor the temperature change versus time. The electrical anode current was recorded for estimating RF power changes in 4-thickness samples. Each RF treatment was replicated three times.

\section{$R F$ heating in two type samples with two moisture content levels}

To determine the effect of different moisture content in milled rice and different type of samples on the RF heating uniformity, the container was vertically separated into two equal sections by a piece of plastic foam board (dimension $22 \times 8 \times 2 \mathrm{~cm}^{3}$ ) (Fig. 3). The left section was filled with the milled samples of $11 \%$ w.b. moisture content and the right section was loaded with that of $9 \%$ w.b. moisture content. Another test with two types of samples both with $9 \%$ w.b. moisture content was conducted to determine the effect of mixed products on the RF heating uniformity (Fig. 4). The surface temperature of soybean in the left section and milled rice in the right one were recorded by the thermal imaging camera. All the samples with thickness of $4 \mathrm{~cm}$ were RF treated under the electrode gap of $120 \mathrm{~mm}$ for $5 \mathrm{~min}$. Each test was replicated three times.

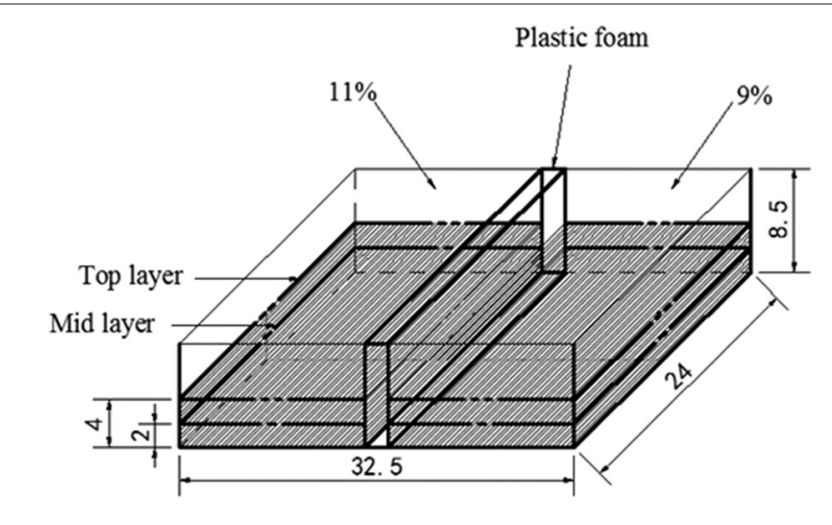

Fig 3. Rectangular plastic container separated into two layers and two sample sections with two different moisture contents of milled rice for surface temperature measurements (all dimensions are in $\mathrm{cm}$ ).
Evaluation of RF heating uniformity by placing low moisture samples in the corners

Based on the pretreatment results and above observations, the RF overheating in corners was found in the rectangular container of dry samples. According to the dielectric heating theory, the higher moisture products would absorb more RF energy than lower moisture samples under the same electromagnetic field. To further determine and improve the RF heating uniformity, rice samples with $9 \%$ w.b. moisture content were placed in four corners of the container and the samples with $11 \%$ w.b. moisture content were filled in left space of the container (Fig. 5). After the RF heating of rice samples with the thickness of $2 \mathrm{~cm}$, the horizontal surface temperature distribution in the top layer was obtained using the infrared camera. The sample temperatures in 9 locations of the middle layer were obtained by a thin Type-T thermocouple thermometer (Fig. 5). The entire measurement process of the experiment was completed within $30 \mathrm{~s}$. The whole experiment was repeated three times.

\section{Heating uniformity}

To evaluate the RF heating uniformity of treated samples at different final temperatures, the heating uniformity index has been proposed by Wang et al. (2005) and used in many studies (Hou et al., 2014; Jiao et al., 2012; Pan et al., 2012;

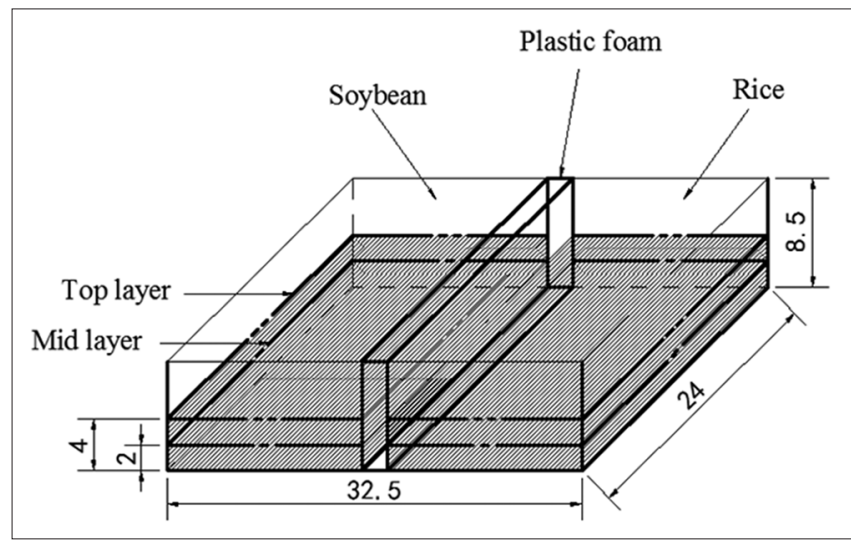

Fig 4. Rectangular plastic container separated into two layers and two sample sections with milled rice and soybeans for surface temperature measurements (all dimensions are in $\mathrm{cm}$ ).

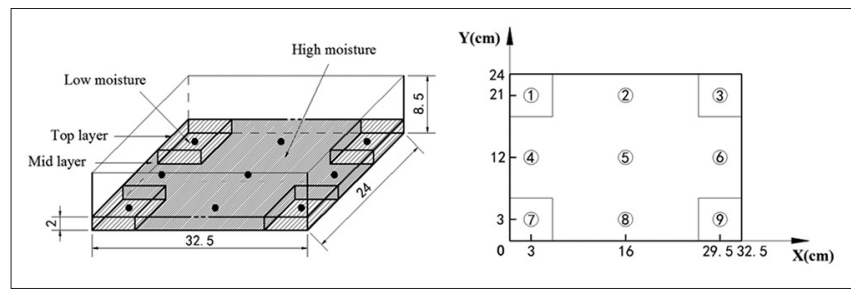

Fig 5. Schematic and top views of 9 locations for temperature measurements in the rectangular plastic container with low moisture content milled rice samples in the four corners and high moisture content samples in the middle for RF treatments (all dimensions are in $\mathrm{cm})$. 
Wang et al., 2008). It is defined as the ratio of the rise in standard deviation of sample temperatures to the rise in the average sample temperatures during treatment and can be calculated by the following equation (Wang et al., 2005):

$$
\lambda=\frac{\sqrt{\sigma^{2}-\sigma_{0}^{2}}}{\mu-\mu_{0}}
$$

Where $\mu_{0}$ and $\mu$ are the initial and final mean rice temperatures $\left({ }^{\circ} \mathrm{C}\right), \sigma_{0}$ and $\sigma$ are initial and final standard deviations $\left({ }^{\circ} \mathrm{C}\right)$ of milled rice and soybean temperatures over treatment time. The smaller $\lambda$ values show the better RF heating uniformity.

\section{RESULTS AND DISCUSSION}

\section{Experimental temperature distribution of milled rice with different thickness}

Fig. 6 shows the experimental temperature distribution of milled rice with four thicknesses in two horizontal layers after $5 \mathrm{~min}$ RF heating at an electrode gap of $120 \mathrm{~mm}$. The corner and edge heating was observed both in top and middle layers of samples with 4 thicknesses. These phenomena were also

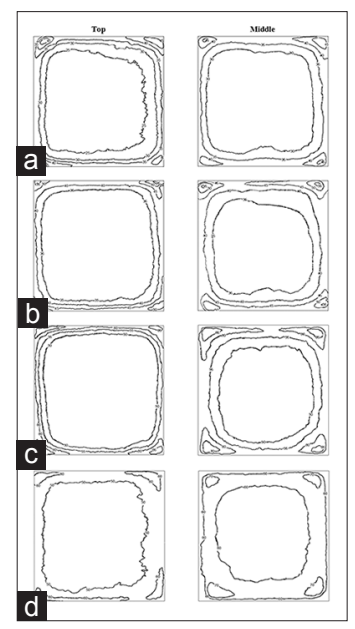

Fig 6. Experimental surface temperature distribution $\left({ }^{\circ} \mathrm{C}\right)$ of milled rice with thicknesses of $2 \mathrm{~cm} \mathrm{(a),} 4 \mathrm{~cm}$ (b), $6 \mathrm{~cm}$ (c), and $8 \mathrm{~cm}$ (d) in top and middle layers placed in a polypropylene container $\left(32.5 \times 24 \times 8.5 \mathrm{~cm}^{3}\right)$ on the bottom electrode, after 5 min RF heating with an initial temperature of $25^{\circ} \mathrm{C}$ and an electrode gap of $120 \mathrm{~mm}$. reported in RF treated chestnut (Hou et al., 2014), coffee bean (Pan et al., 2012), rice (Zhou et al., 2015), soybean (Huang et al., 2015a, b; Wang et al., 2015; Zhu etal., 2014), and wheat flour (Tiwari et al., 2011). The temperature in the middle layer was higher than that in the top layer for each sample with 4 thicknesses (Table 1), which was probably caused by the concentrated electromagnetic fields in the bottom layer of the samples due to direct contact with the bottom electrode, and heat loss of hot surface samples to the ambient air. The average temperatures both in top and middle layers increased with increasing thickness since the electrical current in samples with thicknesses of $2,4,6$, and $8 \mathrm{~cm}$ was $0.27,0.30,0.34$, and $0.39 \mathrm{~A}$, respectively. The heating uniformity was also gradually improved with increased sample thickness based on the reduced uniformity index observed (Table 1). This suggests that the full and thick samples used in industrial applications would achieve a better RF heating uniformity.

\section{Experimental temperature distribution of milled rice with different moisture content}

Fig. 7 shows the experimental temperature distribution of milled rice with two moisture contents of $9 \%$ and $11 \%$ w.b. after 5 min RF heating. The similar heating pattern with edge and corner effects was obtained for two moisture samples separated in the container. The corner effect was also found near the plastic foam for separations. The temperatures in higher moisture $(11 \%$ w.b.) milled rice (left side) were larger than those in lower moisture (9\%) samples both in top and middle layers (Table 2). The RF heating uniformity in the middle layer was better than that in the top layer both in two moisture samples. Because the loss factor of samples increases with increasing moisture content (Guo et al., 2010; Jiao et al., 2011), it is possible to adjust the RF heating rates in samples by controlling the sample moisture contents under the given electric field intensity in validation studies (Jiao et al., 2011).

Experimental temperature distribution of milled rice and soybean with the same moisture content and thickness

Fig. 8 illustrates experimental surface temperature distributions of soybean and milled rice in top and middle layers placed in a polypropylene container on the bottom

Table 1: Comparison of the temperature and heating uniformity index (mean \pm SD over 3 replicates) of milled rice with $9 \%$ w.b moisture content after RF heating with different thickness

\begin{tabular}{|c|c|c|c|c|}
\hline \multirow[t]{2}{*}{ Sample layer } & \multicolumn{4}{|c|}{ Thickness (cm) } \\
\hline & 2 & 4 & 6 & 8 \\
\hline \multicolumn{5}{|c|}{ Temperature $\left({ }^{\circ} \mathrm{C}\right)$} \\
\hline Top & $32.4 \pm 4.9$ & $45.2 \pm 5.9$ & $51.4 \pm 6.8$ & $63.0 \pm 4.9$ \\
\hline Middle & $33.6 \pm 4.7$ & $48.6 \pm 5.4$ & $54.7 \pm 5.8$ & $71.1 \pm 5.2$ \\
\hline \multicolumn{5}{|c|}{ Heating uniformity index $(\lambda)$} \\
\hline Top & $0.657 \pm 0.040$ & $0.290 \pm 0.001$ & $0.254 \pm 0.016$ & $0.127 \pm 0.020$ \\
\hline Middle & $0.539 \pm 0.006$ & $0.301 \pm 0.008$ & $0.192 \pm 0.013$ & $0.112 \pm 0.021$ \\
\hline
\end{tabular}


electrode after 5 min RF heating with an electrode gap of $120 \mathrm{~mm}$. The similar temperature distributions with corner and edge heating were observed both for soybean (left section) and milled rice (right section) samples and in top and middle layers. Experimental results demonstrated that the temperatures of milled rice were higher than those in soybeans (Fig. 8 and Table 3), which was probably caused by the higher loss factor of milled rice than that of soybean at this frequency and moisture levels (Ahmed et al., 2007; Guo et al., 2010). In RF treatments, heating rates in mixed

Table 2: Comparison of the temperature and heating uniformity index (mean $\pm S D$ over 3 replicates) of milled rice with thickness of $4 \mathrm{~cm}$ and two moisture contents after RF heating

\begin{tabular}{lcc}
\hline Sample layer & \multicolumn{2}{c}{ Moisture content (\% w.b.) } \\
\cline { 2 - 3 } & 9 & 11 \\
\hline Temperature $\left({ }^{\circ} \mathrm{C}\right)$ & & \\
$\quad$ Top & $45.4 \pm 4.4$ & $48.2 \pm 5.0$ \\
Middle & $51.9 \pm 3.9$ & $53.6 \pm 4.7$ \\
Heating uniformity index $(\lambda)$ & & \\
Top & $0.213 \pm 0.009$ & $0.212 \pm 0.007$ \\
Middle & $0.143 \pm 0.011$ & $0.160 \pm 0.009$ \\
\hline
\end{tabular}

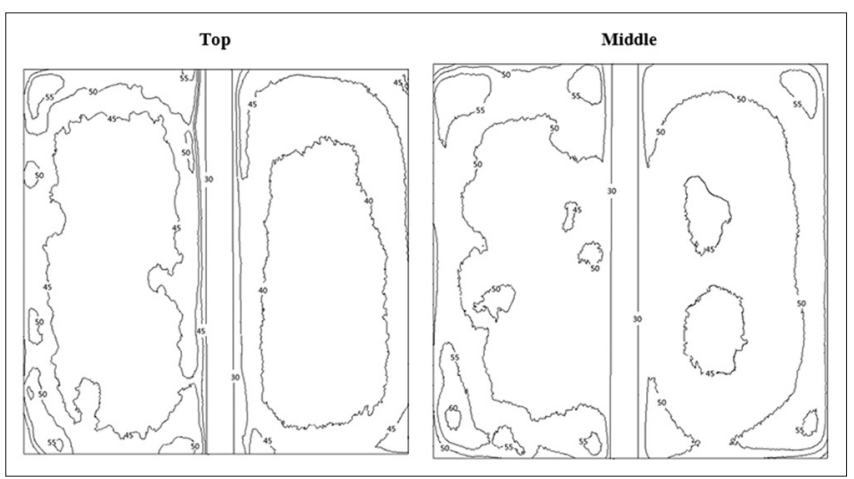

Fig 7. Experimental surface temperature distribution $\left({ }^{\circ} \mathrm{C}\right)$ of milled rice with two moisture contents of $9 \%$ (right side) and $11 \%$ (left side) w.b. in top and middle layers placed in a polypropylene container $\left(32.5 \times 24 \times 8.5 \mathrm{~cm}^{3}\right)$ on the bottom electrode, after $5 \mathrm{~min} R \mathrm{RF}$ heating with an initial temperature of $25^{\circ} \mathrm{C}$ and an electrode gap of $120 \mathrm{~mm}$.

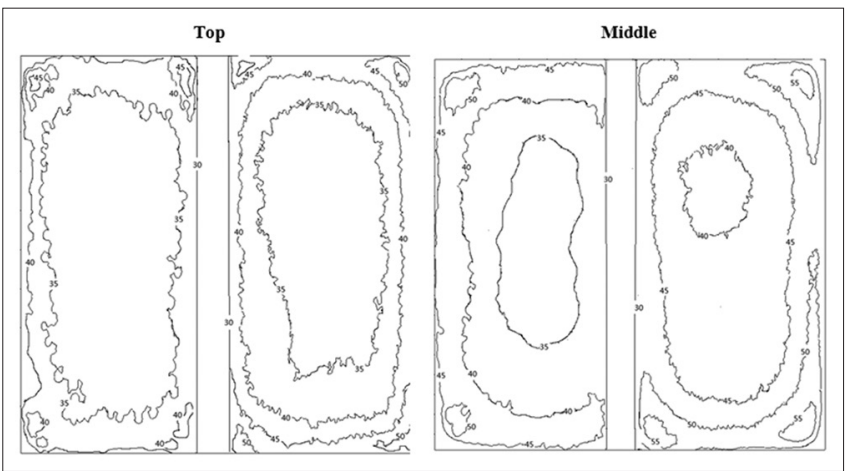

Fig 8. Experimental surface temperature distribution $\left({ }^{\circ} \mathrm{C}\right)$ of soybean (left side) and milled rice (right side) in top and middle layers placed in a polypropylene container $\left(32.5 \times 24 \times 8.5 \mathrm{~cm}^{3}\right)$ on the bottom electrode, after 5 min RF heating with an initial temperature of $25^{\circ} \mathrm{C}$ and an electrode gap of $120 \mathrm{~mm}$. samples are proportional to the dielectric loss factor of individual beans (Huang et al., 2015). It is a good way to keep mixed samples with similar dielectric properties to achieve the required RF heating uniformity.

\section{Improvement of the RF heating uniformity with non- uniform moisture samples}

Fig. 9 shows the experimental surface temperature distributions of $2 \mathrm{~cm}$ thick milled rice on the top layer with uniform moisture (Fig. 2) and the non-uniform moisture sample (Fig. 5) after 5 min RF heating. By placing the low moisture samples in four corners, the general heating pattern was similar (Fig. 9a, b), but the sample temperature in the corners was clearly reduced since lower moisture sample absorbed less RF energy. In addition, the sample temperature in central parts slightly increased, but the average sample temperature was reduced from 34.7 (Fig. 9a) to $32.9^{\circ} \mathrm{C}$ (Fig. 9b) with large decreases in standard deviation values (Table 4). The sample temperatures at 9 locations showed similar patterns both for measurements from thermocouples (Fig. 10a) and thermal images (Fig. 10b). The temperatures in corners (locations of 1,3, 7 and 9) were higher than those in other locations but the difference was reduced when placing low moisture samples in the corners (Fig. 10b). The heating uniformity index was clearly reduced from 0.174 for uniform moisture samples (Fig. 2) to 0.072 for non-uniform ones (Fig. 5) (Table 4).

\begin{tabular}{|c|c|c|}
\hline \multirow[t]{2}{*}{ Sample layer } & \multicolumn{2}{|c|}{ Agricultural products } \\
\hline & Milled rice & Soybean \\
\hline \multicolumn{3}{|c|}{ Temperature $\left({ }^{\circ} \mathrm{C}\right)$} \\
\hline Top & $45.2 \pm 5.0$ & $41.0 \pm 3.8$ \\
\hline Middle & $50.2 \pm 4.1$ & $44.9 \pm 4.3$ \\
\hline \multicolumn{3}{|c|}{ Heating uniformity index $(\lambda)$} \\
\hline Top & $0.242 \pm 0.007$ & $0.234 \pm 0.019$ \\
\hline Middle & $0.159 \pm 0.003$ & $0.218 \pm 0.015$ \\
\hline
\end{tabular}

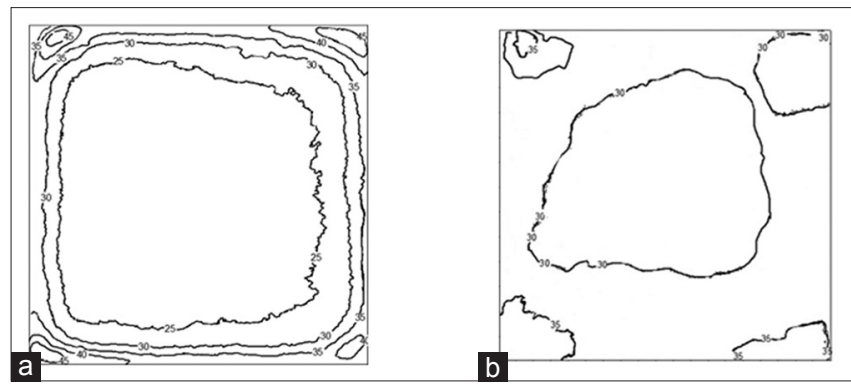

Fig 9. Experimental surface temperature distribution $\left({ }^{\circ} \mathrm{C}\right)$ of $2 \mathrm{~cm}$ thick milled rice on the top layer with uniform moisture (Fig. 2) and the nonuniform moisture sample (Fig. 5) after 5 min RF heating. 
Table 4: Comparison of the temperature and heating uniformity index of $2 \mathrm{~cm}$ thick milled rice with two samples and measurement methods after RF heating

\begin{tabular}{lcc}
\hline Samples & \multicolumn{2}{c}{ Measurement methods } \\
\cline { 2 - 3 } & Thermocouples & Thermal images \\
\hline Temperature $\left({ }^{\circ} \mathrm{C}\right)$ & & \\
$\quad$ Uniform samples (Fig. 2) & $36.3 \pm 6.3$ & $34.7 \pm 6.0$ \\
Non-uniform samples (Fig. 5) & $34.1 \pm 2.5$ & $32.9 \pm 2.4$ \\
Heating uniformity index ( $\lambda$ ) & & \\
Uniform samples (Fig. 2) & 0.174 & 0.173 \\
Non-uniform samples (Fig. 5) & 0.072 & 0.072 \\
\hline
\end{tabular}

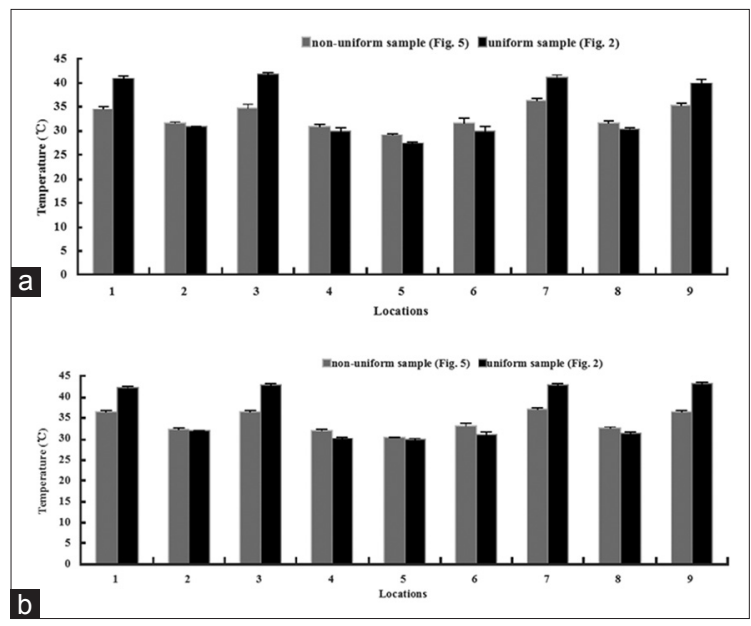

Fig 10. Temperature comparisons at nine locations of RF heated milled rice between uniform moisture sample (Fig. 2) and the non-uniform moisture sample (Fig. 5) measured by thermal imaging camera (a) and thermocouples (b).

\section{CONCLUSIONS}

To simulate industrial applications, the three group RF heating experiments were conducted on temperature distributions of low moisture agricultural products under different thickness, moisture and samples. The results showed that the corner and edge heating was obtained in all these three experiments. The average sample temperature increased with increasing sample thickness. The higher moisture content and higher loss factor resulted in higher sample temperatures. By placing low moisture samples in the four corners, the RF heating uniformity was greatly improved as compared to the uniform moisture samples in the rectangular container. Further research is needed to optimize the heating process and sample property parameters using computer simulation to further improve the RF heating uniformity.

\section{ACKNOWLEDGEMENTS}

This research was conducted in College of Mechanical and Electronic Engineering, Northwest A\&F University, Yangling, China. This research was supported by research grants from General Program of National Natural Science Foundation in China (31371853) and Program of Introducing International Advanced Agricultural Science and Technologies (948 Program) of Ministry of Agriculture of China (2014-Z21). We gratefully thank our research team for their helps on data processing and suggestions to improve experimental design.

\section{Author contributions}

P. Zhang conducted temperature uniformity tests and data analysis. H. Zhu helped the temperature measurements and RF system operations. S. Wang was the project director and guided the overall experimental design and interpretation of RF heating uniformity results.

\section{REFERENCES}

Alfaifi, B., J. Tang, Y. Jiao, S. J. Wang, B. Rasco, S. S. Jiao and S. Sablani. 2014. Radio frequency disinfestation treatments for dried fruit: Model development and validation. J. Food Eng. 120: 268-276.

Ahmed, J., H. S. Ramaswamy and V. G. S. Raghavan. 2007. Dielectric properties of Indian Basmati rice flour slurry. J. Food Eng. 80: 1125-1133.

Birla, S., S. Wang and J. Tang. 2008. Computer simulation of radio frequency heating of model fruit immersed in water. J Food Eng. 84(2): 270-280.

Gao, M., J. Tang, J. A. Johnson and S. Wang. 2012. Dielectric properties of ground almond shells in the development of radio frequency and microwave pasteurization. J. Food Eng. 112(4): 282-287.

Guo, W., S. Wang, G. Tiwari, J. A. Johnson and J. Tang. 2010. Temperature and moisture dependent dielectric properties of legume flours associated with dielectric heating. LWT - Food Sci. Technol. 43(2): 193-201.

Hou, L., B. Ling and S. Wang. 2014. Development of thermal treatment protocol for disinfesting chestnuts using radio frequency energy. Postharvest Biol. Technol. 98: 65-71.

Huang, Z., H. Zhu and S. Wang. 2015a. Finite element modelling and analysis of radio frequency heating rate in mung beans. Trans. Am. Soc. Agric. Biol. Eng. 58(1): 149-160.

Huang, Z., H. Zhu, R. Yan and S. Wang. 2015b. Simulation and prediction of radio frequency heating in dry soybeans. Biosyst. Eng. 129: 34-47.

Jeong, S. G. and D. H. Kang. 2014. Influence of moisture content on inactivation of Escherichia coli O157: H7 and Salmonella enterica serovar Typhimurium in powdered red and black pepper spices by radio-frequency heating. Int. J. Food Microbiol. 176: 15-22.

Jiao, S., Y. Deng, Y. Zhong, D. Wang and Y. Zhao. 2015a. Investigation of radio frequency heating uniformity of wheat kernels by using the developed computer simulation model. Food Res. Int 71: 41-49.

Jiao, S., J. Johnson, J. Tang and S. Wang. 2012. Industrial-scale radio frequency treatments for insect control in lentils. J. Stored Prod. Res. 48: 143-148.

Jiao, S., J. Tang, J. A. Johnson, G. Tiwari and S. Wang. 2011. Determining radio frequency heating uniformity in mixed beans for disinfestations. Trans. Am. Soc. Agric. Biol. Eng. 54(5): 1847-1855. 
Jiao, Y., H. Shi, J. Tang, F. Li and S. Wang. 2015b. Improvement of radio frequency (RF) heating uniformity on low moisture foods with Polyetherimide (PEI) blocks. Food Res. Int. 74: 106-114.

Jiao, Y., J. Tang and S. Wang. 2014. A new strategy to improve heating uniformity of low moisture foods in radio frequency treatment for pathogen control. J. Food Eng. 141: 128-138.

Johnson, J., S. Wang and J. Tang. 2003. Thermal death kinetics of fifth-instar Plodia interpunctella (Lepidoptera: Pyralidae). J. Econ. Entomol. 96(2): 519-524.

Kim, S. Y., H. G. Sagong, S. H. Choi, S. Ryu and D. H. Kang. 2012. Radio-frequency heating to inactivate Salmonella Typhimurium and Escherichia coli O157: $\mathrm{H} 7$ on black and red pepper spice. Int. J. Food Microbiol. 153(1-2): 171-175.

Lagunas-Solar, M. C., Z. Pan, N. X. Zeng, T. D. Truong, R. Khir and K. S. P. Amaratunga. 2007. Application of radio frequency power for non-chemical disinfestation of rough rice with full retention of quality attributes. Appl. Eng. Agric. 23(5): 647-654.

Ling, B., L. Hou, R. Li and S. Wang. 2014. Thermal treatment and storage condition effects on walnut paste quality associated with enzyme inactivation. LWT-Food Sci. Technol. 59(2): 786-793.

Metaxas, A. and M. Clee. 1993. Coupling and matching of radio frequency industrial applicators. Power Eng. J. 7(2): 85-93.

Pan, L., S. Jiao, L. Gautz, K. Tu and S. Wang. 2012. Coffee bean heating uniformity and quality as influenced by radio frequency treatments for postharvest disinfestations. Trans. Am. Soc. Agric. Biol. Eng. 55(6): 2293-2300.

Shrestha, B. and O. D. Baik. 2013. Radio frequency selective heating of stored-grain insects at $27.12 \mathrm{MHz}$ : A feasibility study. Biosyst. Eng. 114(3): 195-204.

Tiwari, G., S. Wang, B. L. Birla and J. Tang. 2008. Effect of waterassisted radio frequency heat treatment on the quality of 'Fuyu' persimmons. Biosyst. Eng. 100(2): 227-234.

Tiwari, G., S. Wang, J. Tang and S. Birla. 2011. Computer simulation model development and validation for radio frequency (RF) heating of dry food materials. J. Food Eng. 105(1): 48-55.

Wang, K., L. Chen, W. Li and S. Wang. 2015. Evaluating the top electrode voltage distribution uniformity in radio frequency systems. J. Electromagn. Waves Appl. 29: 763-773.

Wang, S., B. L. Birla, J. Tang and J. D. Hansen. 2006. Postharvest treatment to control codling moth in fresh apples using water assisted radio frequency heating. Postharvest Biol. Technol. 40(1): 89-96.

Wang, S., K. Luechapattanaporn and J. Tang. 2008. Experimental methods for evaluating heating uniformity in radio frequency systems. Biosyst. Eng. 100(1): 58-65.

Wang, S., M. Monzon, J. Johnson, E. Mitcham and J. Tang. 2007. Industrial-scale radio frequency treatments for insect control in walnuts: II: Insect mortality and product quality. Postharvest Biol. Technol. 45(2): 247-253

Wang, S. and J. Tang. 2001. Radio frequency and microwave alternative treatments for insect control in nuts: A review. Agric. Eng. J. 10(3\&4): 105-120.

Wang, S., J. Tang, J. A. Johnson, E. Mitcham, J. D. Hansen, R. P. Cavalieri, J. Bower and B. Biasi. 2002. Process protocols based on radio frequency energy to control field and storage pests in in-shell walnuts. Postharvest Biol. Technol. 26(3): 265-273.

Wang, S., G. Tiwari, S. Jiao, J. A. Johnson and J. Tang. 2010. Developing postharvest disinfestation treatments for legumes using radio frequency energy. Biosyst. Eng. 105(3): 341-349.

Wang, S., J. Yue, J. Tang and B. Chen. 2005. Mathematical modelling of heating uniformity for in-shell walnuts subjected to radio frequency treatments with intermittent stirrings. Postharvest Biol. Technol. 35(1): 97-107.

Wang, Y. Y., L. Zhang, M. X. Gao, J. Tang and S. Wang. 2014. Evaluating radio frequency heating uniformity using polyurethane foams. J. Food Eng. 136: 28-33.

Zhou, L., B. Ling, A. Zheng, B. Zhang and S. Wang. 2015. Developing radio frequency technology for postharvest insect control in milled rice. J. Stored Prod. Res. 62: 22-31.

Zhu, H., Z. Huang and S. Wang. 2014. Experimental and simulated top electrode voltage in free-running oscillator radio frequency systems. J. Electromagn. Waves Appl. 28(5): 606-617. 